industriously circulated as to the Patagonian guardians of that celebrated asylum.*

When Dr. Stewart says, "That nonrestraint is the rule, and restraint the exception, in his establishment, but that it would be a want of candour to state that the former could be practised, or is practised, every day in the year, with every case in the house," he must pardon me for doubting the correctness of the words in italics. The average daily number of patients in his asylum, during the year 1840 , was 240 ; the average number in Hanwell, 835 ; and it has, says Dr. Conolly, " been fond practicable to control every variety of case, without any fatal accident or serious outrage having occurred;" and "always (it must be remembered) with this consideration, that a change of plan, involving the minutest as well as the most important parts of discipline, is only in progress, and not yet completed."

There is much valuable information contained in this Report of Dr. Stewart, and many useful tables are appended; but $I$ deeply regret that no table has been published, showing the quantity and nature of the restraints used in his asylum. In one of Lord Normanby's trimming letters to the president of Bethlem Hospital, he states, that in all well-regulated asylums in Ireland correct journals are kept of all restraints inflicted; and every body knows that Belfast justly maintains a very high reputation amongst them. It is sumetimes said that doctors will not take their own physic; and if Dr. Stewart should favour the public in his next Report with an abstract of his restraint journal, I think he will not greally increase its bulk. The entries in journals of this nature are, I rejoice to say, in every asylum (Bethlem included), becoming "fine by degrees, and beantifully less;" but it would be great irjustice to $\mathrm{Dr}$. Stewart, to rank him as a reluctant adherent to the humane system. He is an excellent man, full of intelligence, and, in practice, whatever he may write of " the dangerous hallucinations of that monomania of the present day, non-restraintism," an able supporter of moral treatment. The system is, in truth, rapidly advancing, though yet far from general adoption.

A few days ago the "Looker-on" overheard a medrcal man remark to his neighbour, "These people are doing a great deal

* Frequent onportunities, during the performance of judicial duties, at this asylum, enable us to support the remark of our correspondent, by saying, that amongst other things for which the establishment is remarkable, is the personal appearance and demeanour of the nurses and keepers, which are, in a bigh degree, superior and prepossessing, and indicate the exercise of peculiar care and judgment in the selection. of good after all; the keepers of licensed houses are becoming ashamed of their restraints, and lessening or inventing excuses for them; where a strap used to be a foot long it is now a yard; and so on : the old system seems breaking down every where." 'Tis a consummation, Mr. Euitor, devoutly to be wished, and that not only as far as the insane themselves are concerned, but as regards the keepers and nurses; for, when thoroughly understood, and uniformly acted upon, the system diminishes the anxieties of the keepers and nurses, as much as it promotes the comforts of their patients. I am, your obedient servant,

May 11, 1811.

A Looker-on.

\section{MEANS OF RESUSCITATION IN ASPHYXIA.}

\section{To the Editor of THE LANCET.}

SIR:-Having observed in the Number of The LANCET for 20tb March last, p. 880, a valuable letter on this important subject by Mr. C. Searle, of Bath, I beg, through the medium of your pages, to draw the attention of the medical profession to an instrument which, I trust, will, on tcial, effectually accomplish the most essential processes necessary to restore suspended animation. This instrument has been approved by the late Sir A. Cooper, by Sir Heary Halford, Sir James Macgregor, Sir W. Burnett, Sir J. Clarke, Sir John Webb, Drs. James Johnson, Outram, Copland, Mayo, Davies, and many other eminent gentlemen of the profession.

It appears now admitted on all hands, that death in cases of suspended animation principally ensues, in consequence of the want of the necessary mechanical means of keeping up artificial respiration with warm moist air (with an admixture of oxygen), and thereby imparting to the blood that chemical property which natural respiration effects.

To effect this, I have constructed an instrument upon the same principle as my stomach-pump. It is formed of two cylinders, each containing forty cubic inches; so that, on the ascent of the piston, forty cubic inches, or less, of air or fluid are extracted from the trachea and lungs (through a pipe lying on the tongue over the entrance of the trachea); and on the descent of the piston the same quantity of medicated warm air is passed into the trachea and lungs through the nostrils or mouth.

The medicated air is contained in an airproof bag, to be attached to one of the cylinders. Every supply of air is pure and fresh; the air extracted from the lungs is not again returned.

It seems to me most important, that the stagnant fluid and vitiated air should be 
first extracted. The first operation of this instrument, extraction, is performed by raising the piston; the second, inflation, by depressing the piston: thus establishing, through the instrument, artificial respiration for any length of time.

By suspending the action of one of the pistons, extraction or inflation may alone be carried on.

With the same instrument warm stimulants may be passed into the bowels and stomach, and with as great facility, and, perhaps, greater expedition, than by means of my stomach-pump.

In p. 49 of the Number of ThE LANCET for 3rd April last, I observe another letter signed "J. Murray," in which the writer, after noticing the valuable letter of $\mathrm{Mr}$. Searle, says, "I am not aware that Mr. Searle has added anything new, or that $I$ have omitted in my pamphlet on suspended animation," and then claims " an invention wherein the syringe is substituted for the bellows," and then adds, "I have yet to learn that this instrument (the syringe) has been in any way improved." If the writer be the same person who charged me, at the annual meeting of the Medical and Surgical Association, held at Liverpool on the 1st of August, 1839, with having, "from reading his book, manufactured a less effective and clumsier apparatus, and endearoured to palm it upon the public as my own."-(See Supplement to Worcester Journal of 1st August, 1839.)

I beg to in form him through your columns, that I have not borrowed the invention from reading his book : my instrument was made long previously, as stated in my reply to his charge.-(See Berrows' Worcester Journal, 15th August, 1839.) It has, however, been since improved, and, as at present combined, will perform the process of inflation and extraction, or either process, without the necessity of changing the position of any part of the instrument.

35, Regent-circus, Piccadilly.

John Read.

NOTE FROM DR. HOCKEN.

\section{To the Editor of TuE LANCET.}

Sir:-In reply to Mr. Dalrymple's remarks * concerning the case (Eliz. Ward) of chronic byaloiditis, allow me to suggest that I have already, in part, answered his objections; and I trust that I can readily convince that gentleman of the truth of the remaining question.

With him I am ready to acknowledge, that the infrequency of opportunities of postmortem observation retarded, and does retard, certain knowledge of the pathology of

* Lancet, vol. ii., 1840-41, p. 270. the deeper-seated tissues; but I still main. tain that accurate observation during life is most frequently sufficient.

The diagnosis of an increase in the quan, tity of the vitreous humour from choroiditis may be found in my third communication on amaurosis.* I there stated that in hydroph. thalmia the sclerotica was dilated and thinned uniformly; but in choroiditis the uniformity was absent, the thinning being irregular; and hence the protrusion first of the ciliary ligament, and then of portions of the choroid constituting hernia scleroticæ.

I have myself never found any difficulty in the diagnosis between an increased quan. tity of the vitreous humour and collections of fluid behind the retina. As Mr. Dalrym. ple justly remarks, the retina is in such cases thrust forwards, and eventually forms an almost solid cord in the centre of the eye. The very advance of the retina, in these cases, is a proof of their nature: I recollect watching a case in which this fact was beautifully and evidently seen, during some two or three weeks; it then became gradually diminished, and the whole globe eventually atrophied-the patient retaining imperfect vision in the organ.

Mr. Wardrop says (Morb. Anat. of Eye, p. 72), that where the fluid collects quickly, it is accompanied by severe pain in the eye and head; the pupil becomes much dilated, and when the disease has far advanced, there is the appearance of an opake body behind the lens from the retina being com. pressed, which in one instance was mis. taken for cataract, and an attempt made to couch it.

In conclusion, I would remark that no important quantity of fluid would collect behind the retina without displacing that tunic, and causing, more or less, displacement and absorption of the vitreous humour; and that, in all such cases, the nature is self-evident, by a careful inspection through the pupil, where the white advancing retina may be recognised at the fundus, since the same causes which displace seem to render it (retina) opake and white.

May 14, 1811.

Edward Hocken, M.D.

PETITION.-THE VACCINATION ACT.

To the Honourable the House of Commons, in Parliament assembled,

The petition of James Bedingreld, M.D., and legally.qualified practitioner of Medicine and Surgery,

Humbly Showeth,

1. That your petitioner regards with bigh satisfaction the recent measure which has been enacted by the Legislature for the pre.

* Vide loc. cit., p. 156. 